\title{
MOVIMENTO ROTACIONAL COM TORQUE DE GRADIENTE DE GRAVIDADE NAS REGIÕES DE LIBRAÇÃO E CIRCULAÇÃO
}

\author{
Mariana A. R. Almeida \\ Faculdade de Engenharia de Guaratinguetá, UNESP \\ 12516-410, Guaratinguetá, SP \\ E-mail: mari.matematica@yahoo.com.br \\ Maria Cecília Zanardi \\ Universidade Federal do ABC, UFABC \\ 09210-580, Santo André, SP \\ E-mail: mceciliazanardi@gmail.com \\ William R. Silva \\ Instituto Nacional de Pesquisas Espaciais, INPE \\ 12227-010, São José do Campos, SP \\ E-mail: reis.william@gmail.com
}

\section{RESUMO}

Neste Trabalho é analisado o comportamento temporal das variáveis que representam o movimento rotacional de um satélite de médio porte não simétrico, sob a ação do torque de gradiente de gravidade, nas regiões de libração e circulação ao redor dor pontos de equilíbrio do sistema. A Hamiltoniana que descreve o movimento é expressa em termos das variáveis canônicas de Andoyer [3], que são importantes em análises envolvendo métodos analíticos de pertubação, e estão indicadas na Figura 1. Neste caso, as aplicações são feitas com o auxílio dos softwares MATLAB e MATHEMATICA

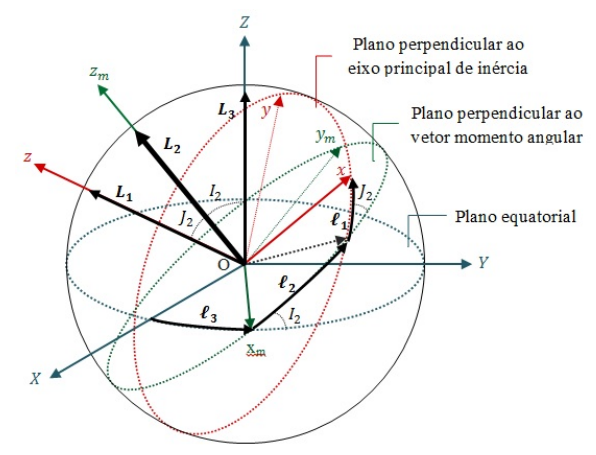

Figura 1: Sistema de Coordenadas, as variáveis angulares de Andoyer $\left(l_{1}, l_{2}, l_{3}\right)$ e as variáveis métricas de Andoyer $\left(L_{1}, L_{2}, L_{3}\right)$

A Hamiltoniana completa com o torque de gradiente de gravidade é apresentada em [2,3], sendo que o comportamento da hamiltoniana $(\mathrm{H})$ em função de $\left(l_{2}, L_{2}\right)$ é discutido e está representado na figura 3, na qual podem ser observadas as regiões de libração e circulação, além da separatriz. Para alguns pontos das regiões de libração e circulação serão analisados o comportamento temporal das variáveis de Andoyer $\left(l_{1}, l_{2}, l_{3}, L_{1}, L_{2}\right.$ e $\left.L_{3}\right)$ e os resultados deverão ser comparados com os resultados obtidos para o movimento rotacional livre de torque externos [1]. Os resultados obtidos são importantes na análise 
da estabilidade do movimento rotacional na presença do torque de gradiente de gravidade e de outros torques externos.

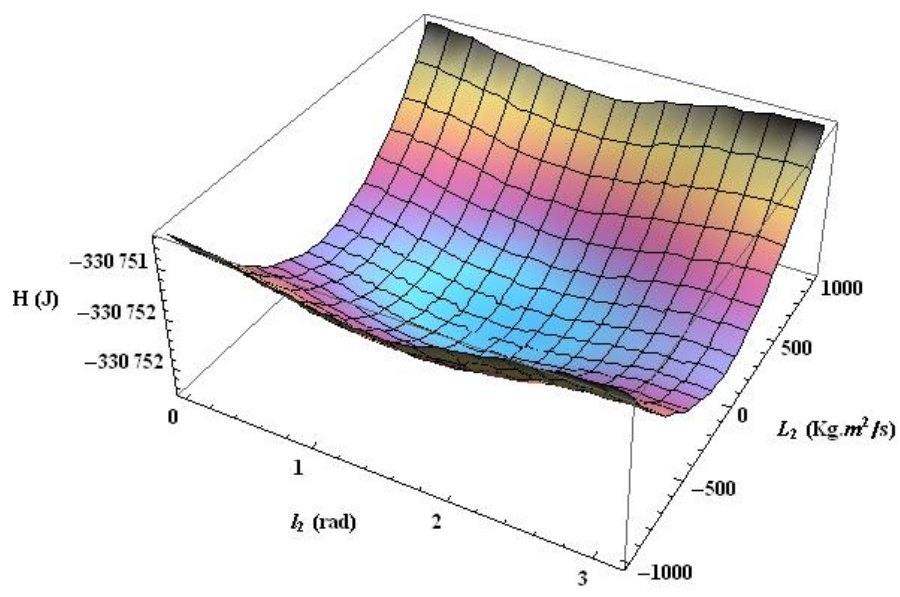

Figura 2: Hamiltoniana do movimento rotacional com torque de gradiente de gravidade em função da variável angular $l_{2}$ e variável métrica $L_{2}$

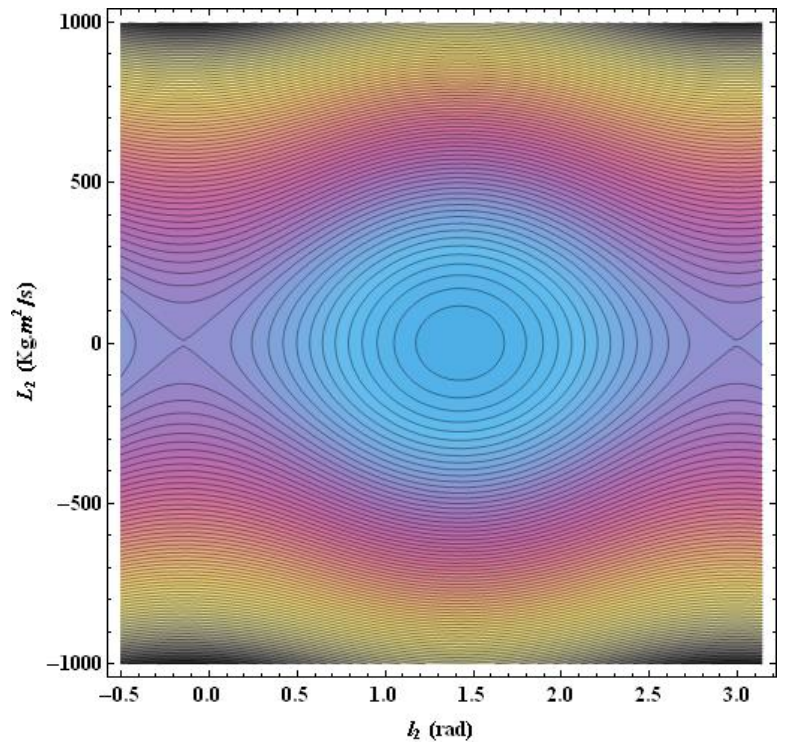

Figura 3: plano de fase $\left(l_{2}, L_{2}\right)$

Palavras-chave: Movimento rotacional, torque de gradiente de gravidade, variáveis de Andoyer, espaço de fase

\section{Referências}

[1] Almeida, M. A. R.: "Evolução do movimento rotacional livre de torques externos nas regiões de libração e circulação", DINCON, Fortaleza, Ceará, (2013).

[2] Silva, W. R.: "Estudo da estabilidade do movimento rotacional de satélites artificiais com variáveis canônicas". Dissertação de mestrado, Universidade Estadual de São Paulo, Guaratinguetá, (2012).

[3] Zanardi, M. C.: "Study of the terms of coupling between rotational and translational motion". Celes. Mech. 39(2), 147-164, (1986). 